\title{
Disparity of autonomic control in type 2 diabetes mellitus
}

Received: 11 June 2004 / Accepted: 9 August 2004 / Published online: 23 December 2004

(C) Springer-Verlag 2004

\begin{abstract}
Aims/hypothesis: Acute insulinaemia activates the sympathetic drive in a nonuniform manner. The extent and nature of such activation in type 2 diabetic patients who do not have neuropathy have not yet been addressed despite evidence relating sympathetic activation to cardiovascular risk. We planned to determine the magnitude and extent of the sympathetic drive and its reflex responses in patients with type 2 diabetes and fasting hyperinsulinaemia. Methods: We measured resting muscle sympathetic nerve activity (MSNA) as the mean frequency of multiunit bursts and single unit muscle sympathetic nerve activity (s-MSNA) in 17 overweight patients with type 2 diabetes and two matched normal control groups comprising 17 overweight and 16 normal-weight subjects. We also tested the MSNA and s-MSNA responses to cold pressor and isometric hand-grip tests, along with the effect of sympatho-vagal balance on heart period variability. Results: Both MSNA and s-MSNA in the group with type 2 diabetes $(66 \pm 3.5$ bursts/100 beats and $78 \pm 4.5$ impulses/100 beats) were greater (at least $p<0.0001$ ) than in the overweight control group ( $42 \pm 2.6$ bursts $/ 100$ beats and $48 \pm 3.4$ impulses/100 beats) and normal-weight control group ( $43 \pm 6.2$ bursts $/ 100$ beats and $51 \pm 7.1$ impulses/100 beats), though the three groups had similar reflex responses, baroreflex sensitivity and sympathovagal balance controlling the heart period. Conclusions/ interpretation: The patients with type 2 diabetes had no evidence of impaired reflex or autonomic control of heart period variability at a time when there was central
\end{abstract}

R. J. Huggett $(\bowtie) \cdot$ J. Bannister · A. F. Mackintosh ·

D. A. S. G. Mary

Department of Cardiology, St. James's University Hospital,

Leeds, LS9 7TF, UK

e-mail: roberthuggett@hotmail.com

Tel.: +44-113-2064864

Fax: +44-113-2066376

E. M. Scott - S. G. Gilbey

Department of Diabetes and Endocrinology, St. James's

University Hospital,

Leeds, UK sympathetic activation to the periphery. Furthermore, being overweight itself was not associated with sympathetic activation.

Keywords Autonomic nervous system - Diabetes mellitus, type $2 \cdot$ Insulin

Abbreviations BRS: baroreceptor reflex sensitivity of vagal effects on the sino-atrial node - CVR: calf vascular resistance $\cdot H F$ : high frequency in power spectral analysis . HOMA-IR: homeostasis model assessment index of insulin resistance $\cdot$ LF: low frequency in power spectral analysis - MSNA: muscle sympathetic nerve activity · s-MSNA: single unit muscle sympathetic nerve activity

\section{Introduction}

Extensive research shows that in normal healthy individuals acute hyperinsulinaemia in itself increases resting sympathetic output [1]. This has been shown using techniques such as venous plasma catecholamine concentration [2] and total body and forearm norepinephrine spillover [3] as well as by direct neural recordings [4, 5]. Experiments involving direct measurement of regional sympathetic nerve activity in animal studies have shown that central and systemic insulinaemia cause preferential stimulation of lumbar but not renal or adrenal regions $[6,7]$. In normal humans and those with insulin resistance it has also been shown that insulinaemia causes nonuniform regional sympathetic activation, with reports showing an increase in output to the forearm and legs but not to the kidneys $[8,9]$. Furthermore indirect studies of the cardiac autonomic nervous system, as measured by spectral analysis of the heart period, have reported that insulinaemia increases sympathetic activity in insulin-sensitive but not in insulin-resistant individuals [10-12].

To the best of our knowledge no studies have addressed the level of autonomic control and extent of sympathetic activity in patients with type 2 diabetes under fasting hyperinsulinaemic conditions. Past studies in patients with 
type 2 diabetes but no neuropathy have reported an increase or a decrease in plasma noradrenaline levels [13-15] and an increase in peripheral muscle sympathetic nerve activity (MSNA) [16]. Also, there are reports that patients with type 2 diabetes have either normal or decreased levels of heart rate variability $[14,17,18]$.

We therefore planned for the first time to determine the magnitude and extent of sympathetic drive and its reflex responses in patients with type 2 diabetes in whom there was no evidence of neuropathy. For this purpose, we measured the mean frequency of MSNA and its reflex responses as well as sympatho-vagal effects on the heart period including the baroreceptor reflex sensitivity of vagal effects (BRS) in a group of patients with type 2 diabetes and hyperinsulinaemia. These data were compared with those of closely matched groups of normal and overweight control subjects.

\section{Subjects and methods}

Subjects We examined 50 Caucasian subjects, including 17 overweight patients with type 2 diabetes, 17 overweight and 16 normal-weight control subjects. All underwent a screening medical history and examination before the study. They were excluded if there was evidence of cardiac dysrhythmias, vascular disease, microalbuminuria, obstructive sleep apnoea and chronic disease likely to influence the autonomic nervous system.

Screening for neuropathy was based on recommendations of the 1988 San Antonio Conference of Diabetic Neuropathy, American Diabetic Association and the American Academy of Neurology [19, 20] with the following categories being measured: symptom profile, conventional neurological examination, and autonomic function testing. Furthermore all subjects increased their arterial pressure and sympathetic nerve activity during an initial screening isometric hand-grip test.

The diagnosis of type 2 diabetes was confirmed as recommended by the American Diabetic Association [21]. In every patient this included a fasting plasma glucose concentration of greater than $7.0 \mathrm{mmol} / \mathrm{l}$ and a 2 -h plasma glucose value after OGTT of greater than $11.1 \mathrm{mmol} / \mathrm{l}$. The patients were diagnosed $35 \pm 6.4$ months previously and their diabetes was well controlled at least over the preceding 6 months (mean $\mathrm{HbA}_{1} \mathrm{c}$ of $\leq 7.8 \pm 0.3 \%$ ). Arterial pressure was determined from the average of at least three seated recordings taken on separate occasions. The three groups were matched in terms of age and sex, while the two overweight groups were also matched in respect of body weight, BMI and waist circumference. The diabetic patients were receiving angiotensin converting enzyme inhibitors $(n=9)$, metformin $(n=9)$, gliclazide $(n=3)$ or combined therapy $(n=2)$. The levels of arterial blood pressure of the diabetic group were similar to those of the two normal control groups.

The investigation was conducted according to the principles of the Declaration of Helsinki (2000) of the World Medical Association and carried out with the approval of
St. James's University Hospital Ethics Committee, with all subjects providing informed written consent.

Assays Fasting plasma insulin, glucose and $\mathrm{HbA}_{1} \mathrm{c}$ levels were obtained through a venous sample. Insulin was measured by solid-phase two-site immunoassay (AutoDELFIA; PerkinElmer Life Sciences, Cambridge, UK). The coefficient of variation of within-assay measurements ranged from $2.1 \%$ to $3.7 \%$, and that between assays ranged from $3.3 \%$ to $3.8 \%$. Blood glucose was measured by auto-analyser (Roche/Hitachi GOD-PAP; Roche Diagnostics, USA), with a coefficient of variation of withinassay measurement of $0.9 \%$. Insulin resistance was assessed by the previously validated $[22,23]$ homeostasis model assessment (HOMA), whereby the HOMA index of insulin resistance $($ HOMA-IR $)=$ fasting glucose $(\mathrm{mmol} / \mathrm{l}) \times($ fasting insulin $[\mu \mathrm{U} / \mathrm{ml}] / 22.5)$.

General protocol Measurements of haemodynamic, microneurographic, and autonomic variables in the two groups were obtained in an identical manner during each session. The details of such sessions have been published previously [16, 24]. Briefly, all investigations were performed under similar conditions between 09.00 and 12.00 hours in order to avoid circadian autonomic variation. Subjects were fasted for $12 \mathrm{~h}$ before the investigations and asked to empty their bladder before commencing the study. The subjects maintained a normal dietary sodium intake of $\approx 150 \mathrm{mmol} / \mathrm{day}$, and they were requested to avoid nicotine, caffeine, alcohol and strenuous exercise for $24 \mathrm{~h}$ prior to investigation.

During each session microneurographic variables, BRS and heart rate variability were obtained with the subjects in the semisupine position. Measurements were taken in a darkened laboratory, in which the temperature was constant at 22 to $24{ }^{\circ} \mathrm{C}$. Resting arterial blood pressure was measured from the arm using a standard mercury sphygmomanometer. Changes in heart rate and arterial blood pressure were monitored and recorded using a standard ECG and a Finometer device (FMS, Arnhem, The Netherlands). Blood flow to the muscle of the left calf was obtained using standard strain-gauge plethysmography (Hokanson, Bellevue, WA, USA).

Microneurography Postganglionic muscle sympathetic nerve activity was recorded from the right peroneal nerve, alongside the other data, as previously described $[16,24]$. The neural signal was amplified $(\times 50,000)$, and for the purpose of generating bursts representing multiunit discharge, the signal was filtered (bandwidth 700 $2,000 \mathrm{~Hz}$ ), and integrated (time constant $0.1 \mathrm{~s}$ ). The output of action potentials and bursts from this assembly was passed to a PC-based data-acquisition system (LabView; National Instruments, Austin, TX, USA), which digitised the acquired data at 12,000 samples/s (16 bits).

MSNA was differentiated from skin sympathetic activity and afferent activity by previously accepted criteria $[25,26]$. Single units of muscle sympathetic nerve activity (s-MSNA) in the raw action potential neurogram were 
obtained by adjusting the electrode position whilst using fast monitor sweep and an on-line storage oscilloscope to confirm the presence of consistent action potential mor- phology, as previously described [16, 24, 26]. Only vasoconstrictor units were accepted and examined; the criteria of acceptance being appropriate responses to
Fig. 1 Examples of recordings obtained in three subjects: type 2 diabetic subject (a), overweight control subject (b), and normal control subject (c). Each panel shows from top to bottom: the ECG, respiratory movements, finger arterial pressure (FBP), multi-unit MSNA (bursts), raw action potential (AP) and time scale. The single units (s-MSNA) can be seen in the raw action potential recordings

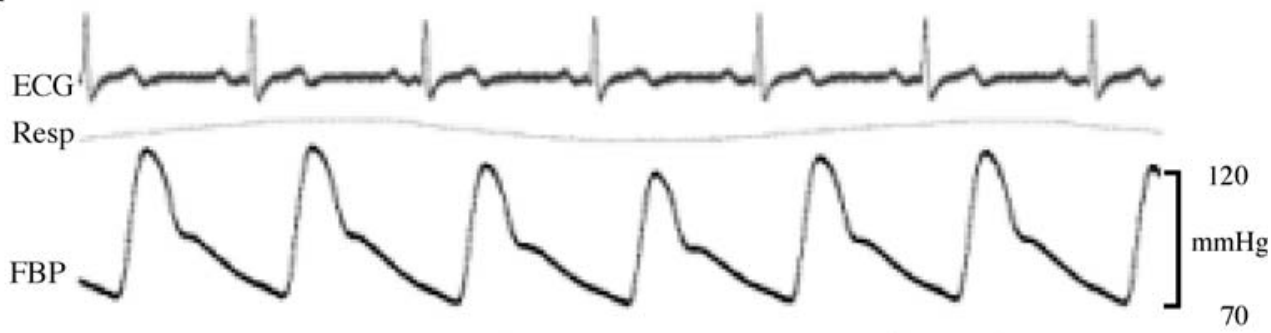

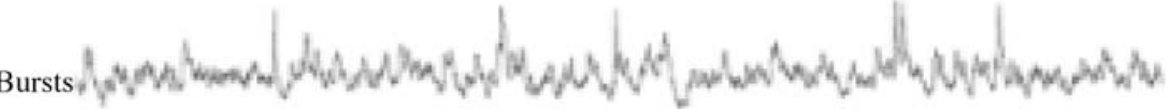

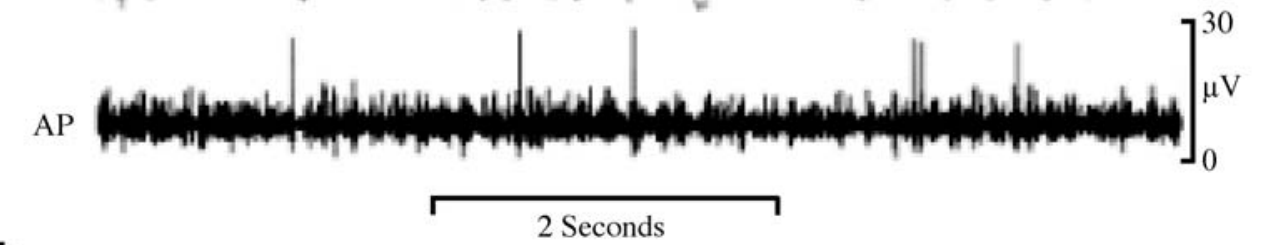

b

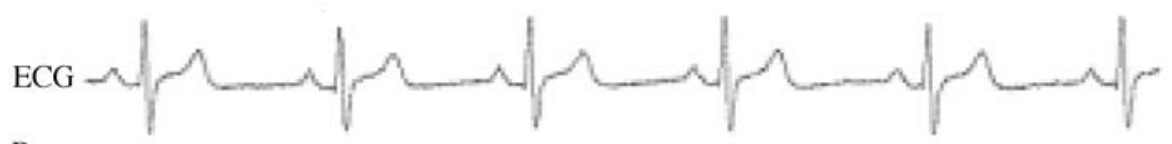

Resp
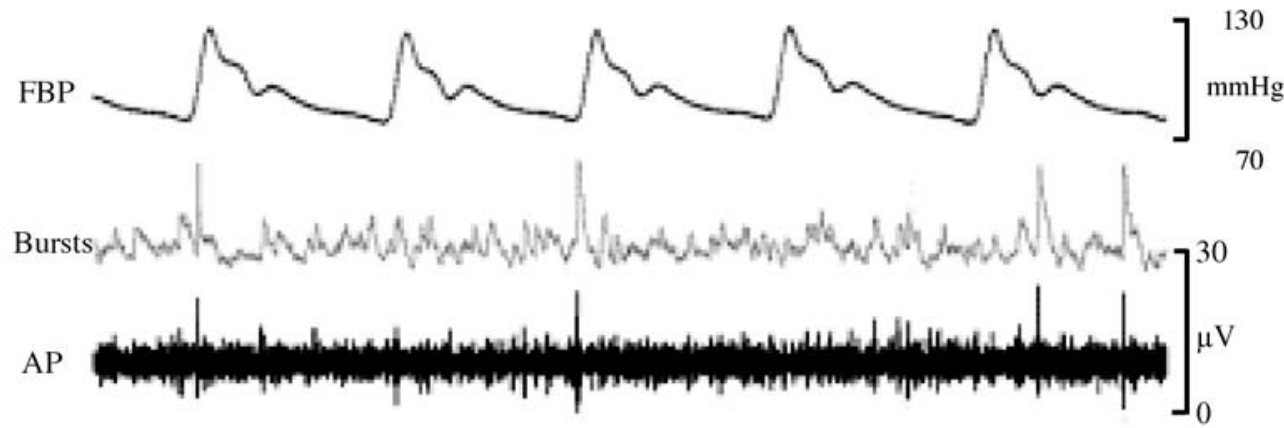

C

2 Seconds
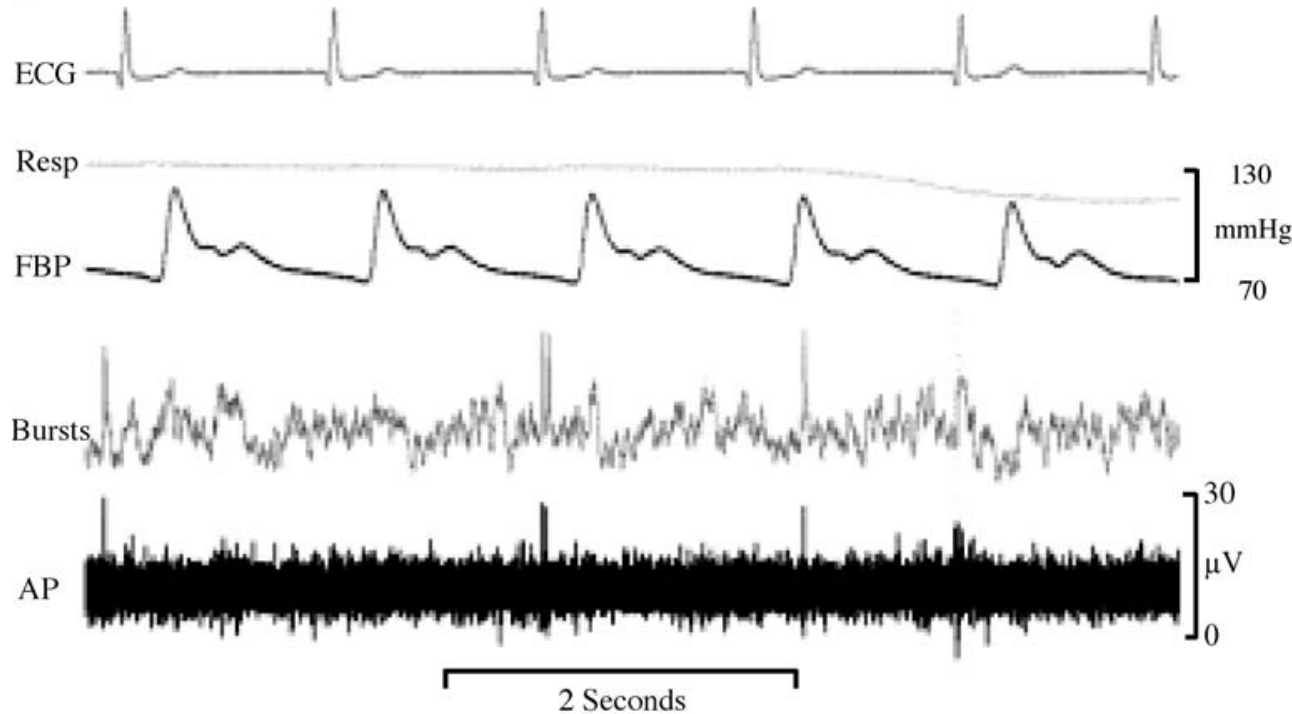

2 Seconds 
spontaneous changes in arterial blood pressure, the Valsalva manoeuvre as well as isometric hand-grip exercise and cold pressor tests. Simultaneous measurement of calf vascular resistance (CVR) confirmed the vasoconstrictor function of the observed neural activity. During the Valsalva manoeuvre, sympathetic activity increased during the latter part of phase II and/or phase III and decreased during phase IV (corresponding to the decrease and increase of arterial pressure). The Valsalva manoeuvre was performed by exhaling for $15 \mathrm{~s}$ into a standard mercury manometer, at a pressure of 40 to $50 \mathrm{mmHg}$. This was monitored by a pneumograph. Examples of recordings in subjects of each of the three groups are shown in Fig. 1.

Analysis was independently performed off-line, using dedicated software based on the LabView system (National Instruments). An electronic discriminator window was used objectively to count the spikes of s-MSNA. This was quantified as the mean frequency of impulses/minute and impulses/100 cardiac beats to avoid any interference by the length of the cardiac cycle [27]. The bursts of MSNA were identified by inspection when the signal-tonoise ratio was greater than 3 . These were counted using an electronic discriminator and quantified in a similar manner to s-MSNA. The variability of s-MSNA and MSNA, which was expressed as $95 \%$ confidence intervals of individual differences between repeated measurements, did not exceed $10 \%$ in this laboratory [24]. CVR was obtained from the product of mean arterial blood pressure and the mean of at least three measurements of calf blood flow.

Baroreceptor reflex sensitivity Baroreceptor reflex sensitivity controlling the heart period through vagal effects was obtained from stage IV of the Valsalva manoeuvre [28]. This was calculated from the slope of the best linear relationship between systolic blood pressure and its heart period (phase 0) or the succeeding one (phase 1).

Isometric exercise and cold pressor test Isometric handgrip exercise was performed using a dynamometer (MIE Medical Research, Leeds, UK), by employing 30\% of a predetermined maximal voluntary contraction for $2 \mathrm{~min}$. The cold pressor test was performed by dipping the subject's hand into cold water at less than $4{ }^{\circ} \mathrm{C}$ for at least 1 min or until discomfort was felt. Baseline and recovery data were taken for 1 min prior to, and after each of, the two tests. The two tests were completed by 15 subjects of each group. The responses of sympathetic nerve activity to the cold pressor test were obtained in 11 subjects of each normal group. The responses of sympathetic nerve activity to the isometric exercise test were obtained in nine subjects of each group. In the remaining patients and normal subjects, it was not possible to measure the activity because of interference by changes in leg muscle tension. Responses to isometric hand-grip exercise were derived from the differences between data obtained during the second minute of the exercise, when sympathetic activity is known to increase [29], and the average of those obtained during baseline and recovery periods. Responses to the cold pressor test were derived as the differences between data obtained during the last $30 \mathrm{~s}$ of exposure to cold, when the occurrence of discomfort is known to be accompanied by an increase of sympathetic activity [30], and the average of those obtained during baseline and recovery periods.

Heart rate variability An ECG and Finometer arterial pressure reading were recorded for $8 \mathrm{~min}$ in each patient. The respiratory frequency was measured with a pneumograph and the patients were asked to breathe at a normal rate. All RR periods were digitised at $250 \mathrm{~Hz}$ using a PCbased acquisition system (LabView; National Instruments).

Table 1 Details of the three groups

\begin{tabular}{|c|c|c|c|c|c|c|}
\hline \multirow[t]{2}{*}{ Subjects } & \multirow[t]{2}{*}{ Type 2 diabetes (A) } & \multirow[t]{2}{*}{ Overweight controls (B) } & \multirow[t]{2}{*}{ Normal-weight controls (C) } & \multicolumn{3}{|l|}{$p$ value } \\
\hline & & & & A vs $B$ & A vs $\mathrm{C}$ & $\mathrm{B}$ vs $\mathrm{C}$ \\
\hline Number (men) & $17(11)$ & $17(8)$ & $16(7)$ & NS & NS & NS \\
\hline Age (years) & $54 \pm 2.6$ & $53 \pm 2.6$ & $51 \pm 3.6$ & NS & NS & NS \\
\hline Body weight (kg) & $88 \pm 4.1$ & $84 \pm 3.8$ & $63 \pm 1.7$ & NS & $<0.001$ & $<0.001$ \\
\hline Body mass index $\left(\mathrm{kg} / \mathrm{m}^{2}\right)$ & $30 \pm 1.1$ & $29 \pm 1.4$ & $22 \pm 0.4$ & NS & $<0.001$ & $<0.001$ \\
\hline Waist circumference $(\mathrm{cm})$ & $97 \pm 1.8$ & $96 \pm 1.5$ & $76 \pm 1.6$ & NS & $<0.001$ & $<0.001$ \\
\hline Heart rate (beats/min) & $71 \pm 1.7$ & $68 \pm 1.7$ & $65 \pm 2.9$ & NS & NS & NS \\
\hline \multicolumn{7}{|l|}{ Arterial pressure (mm Hg) } \\
\hline Mean & $97 \pm 1.3$ & $98 \pm 1.0$ & $96 \pm 1.4$ & NS & NS & NS \\
\hline Systolic & $131 \pm 2.0$ & $132 \pm 1.8$ & $129 \pm 2.5$ & NS & NS & NS \\
\hline Diastolic & $79 \pm 1.3$ & $82 \pm 0.8$ & $79 \pm 1.3$ & NS & NS & NS \\
\hline Fasting insulin $(\mu \mathrm{U} / \mathrm{ml})$ & $15.6 \pm 3.3$ & $6.0 \pm 1.4$ & $5.3 \pm 0.8$ & $<0.05$ & $<0.05$ & NS \\
\hline Fasting glucose $(\mathrm{mmol} / \mathrm{l})$ & $9.8 \pm 1.0$ & $5.1 \pm 0.2$ & $4.7 \pm 0.2$ & $<0.001$ & $<0.001$ & NS \\
\hline HOMA-IR (U) & $7.3 \pm 1.6$ & $1.4 \pm 0.3$ & $1.1 \pm 0.1$ & $<0.01$ & $<0.01$ & NS \\
\hline
\end{tabular}

Data are means \pm SEM. Analyses were performed using ANOVA post hoc tests, except for sex difference in which Fisher's exact test was used. NS denotes $p>0.05$; $p$ values as shown 
Table 2 Resting data of the three groups

\begin{tabular}{|c|c|c|c|c|c|c|}
\hline \multirow[t]{2}{*}{ Subjects } & \multirow[t]{2}{*}{ Type 2 diabetes (A) } & \multirow[t]{2}{*}{ Overweight controls (B) } & \multirow[t]{2}{*}{ Normal-weight controls (C) } & \multicolumn{3}{|l|}{$p$ value } \\
\hline & & & & A vs B & $\mathrm{A}$ vs $\mathrm{C}$ & $\mathrm{B}$ vs $\mathrm{C}$ \\
\hline MSNA (bursts/min) & $46 \pm 1.8$ & $28 \pm 1.6$ & $26 \pm 3.5$ & $<0.001$ & $<0.001$ & NS \\
\hline s-MSNA (impulses/min) & $54 \pm 2.6$ & $32 \pm 2.1$ & $31 \pm 3.6$ & $<0.001$ & $<0.001$ & NS \\
\hline s-MSNA (impulses/100 b) & $78 \pm 4.5$ & $48 \pm 3.4$ & $51 \pm 7.1$ & $<0.001$ & $<0.001$ & NS \\
\hline Low frequency $\left(\mathrm{ms}^{2}\right)$ & $357 \pm 55$ & $454 \pm 98$ & $465 \pm 87$ & NS & NS & NS \\
\hline High frequency $\left(\mathrm{ms}^{2}\right)$ & $180 \pm 56$ & $212 \pm 58$ & $261 \pm 49$ & NS & NS & NS \\
\hline Low frequency (nU) & $69 \pm 5.2$ & $68 \pm 6.2$ & $63 \pm 5.0$ & NS & NS & NS \\
\hline High frequency (nU) & $31 \pm 5.2$ & $32 \pm 6.2$ & $36 \pm 5.0$ & NS & NS & NS \\
\hline Low/high-frequency ratio & $3.6 \pm 0.85$ & $3.8 \pm 1.20$ & $2.9 \pm 1.0$ & NS & NS & NS \\
\hline
\end{tabular}

Muscle sympathetic nerve activity (s-MSNA and MSNA) is expressed as impulses and bursts per minute and 100 cardiac beats (100 b). Spectral analysis presented as total power, absolute and normalised units (nU). BRS baroreceptor reflex sensitivity. Data are means \pm SEM. Analyses were performed using ANOVA post hoc tests. NS denotes $p>0.05 ; p$ values as shown

The RR period series was then resampled at $5 \mathrm{~Hz}$ using a previously described method [31]. A series of overlapping segments each of 512 points and overlapping the previous segment by $78 \%$ was then obtained from the resampled periods. Each segment was detrended to remove any nonvariable component and multiplied by the Hanning window function and then transformed by Fourier's analysis. Low-frequency (LF) and high-frequency (HF) components were defined as the area under the spectrum between 0.04 and $0.15 \mathrm{~Hz}$ and 0.15 and $0.4 \mathrm{~Hz}$, respectively. The area was also calculated as normalised units, total power and the ratio between $\mathrm{LF} / \mathrm{HF}$ as recommended by the European Task Force on heart rate variability [32].

Statistics One-way ANOVA with Newman-Keuls post hoc tests was used to compare data between the three groups. Changes in data in responses to interventions were assessed by Student's $t$-tests for paired variables. The leastsquare technique was used to assess the linear relationship between variables. We considered $p$ values of less than 0.05 to be statistically significant. Data are presented as means \pm SEM.

\section{Results}

The data from the three groups are shown in Table 1. The diabetic group was well matched for age and sex (Fisher's exact test; $p>0.40$ ) to the other two control groups. Also, the diabetic group was well matched for age, body weight, BMI and waist circumference to the overweight normal control group. There were no statistically significant differences between the groups in heart rate or indices of arterial pressure (at least $p>0.05$ ).

The three groups differed in respect of plasma insulin and glucose levels (Table 1). Plasma insulin and glucose levels were greater in the group with type 2 diabetes than the normal values obtained in the two control groups.
Similarly, HOMA-IR was greater in the group with type 2 diabetes than in the two control groups.

All measures of the mean frequency of resting sympathetic nerve activity of s-MSNA and MSNA per minute and per 100 beats were significantly greater in the group with type 2 diabetes (Table 2) than in the two control groups. The sympathetic nerve activity in patients with type 2 diabetes was about two-thirds higher than in normal control groups. Also, a positive correlation was found between sympathetic activity and HOMA-IR or insulin levels ( $r$ between 0.47 and 0.72 ; at least $p<0.04$ ). However, there were no significant differences between the two groups in respect of CVR, BRS and indices of heart rate variability (Table 2).

In all three groups a significant increase in heart rate, arterial pressure, sympathetic activity and CVR was obtained in response to the isometric hand-grip exercise and cold pressor tests (at least $p<0.02$ ). There were no significant differences between the three groups in respect of these responses (Table 3).

\section{Discussion}

Our study demonstrates, for the first time, that patients with type 2 diabetes and fasting hyperinsulinaemia have a within-patient disparity of autonomic control in that there was an abnormal activation of sympathetic drive to the periphery despite the largely intact cardiac autonomic control and reflex responses. The nonuniform abnormality of sympathetic activation is consistent with evidence pointing to an insulin-induced central sympathetic activation with nonuniform involvement of body regions.

By design, our findings were obtained in patients with type 2 diabetes who had no evidence of neuropathy, because this could interfere with autonomic neural control and its effects [33-36]. We used previously accepted criteria $[19,20]$, as well as clinical examination and vasopressor responses, to exclude somatic and autonomic 
Table 3 Reflex responses of the three study groups

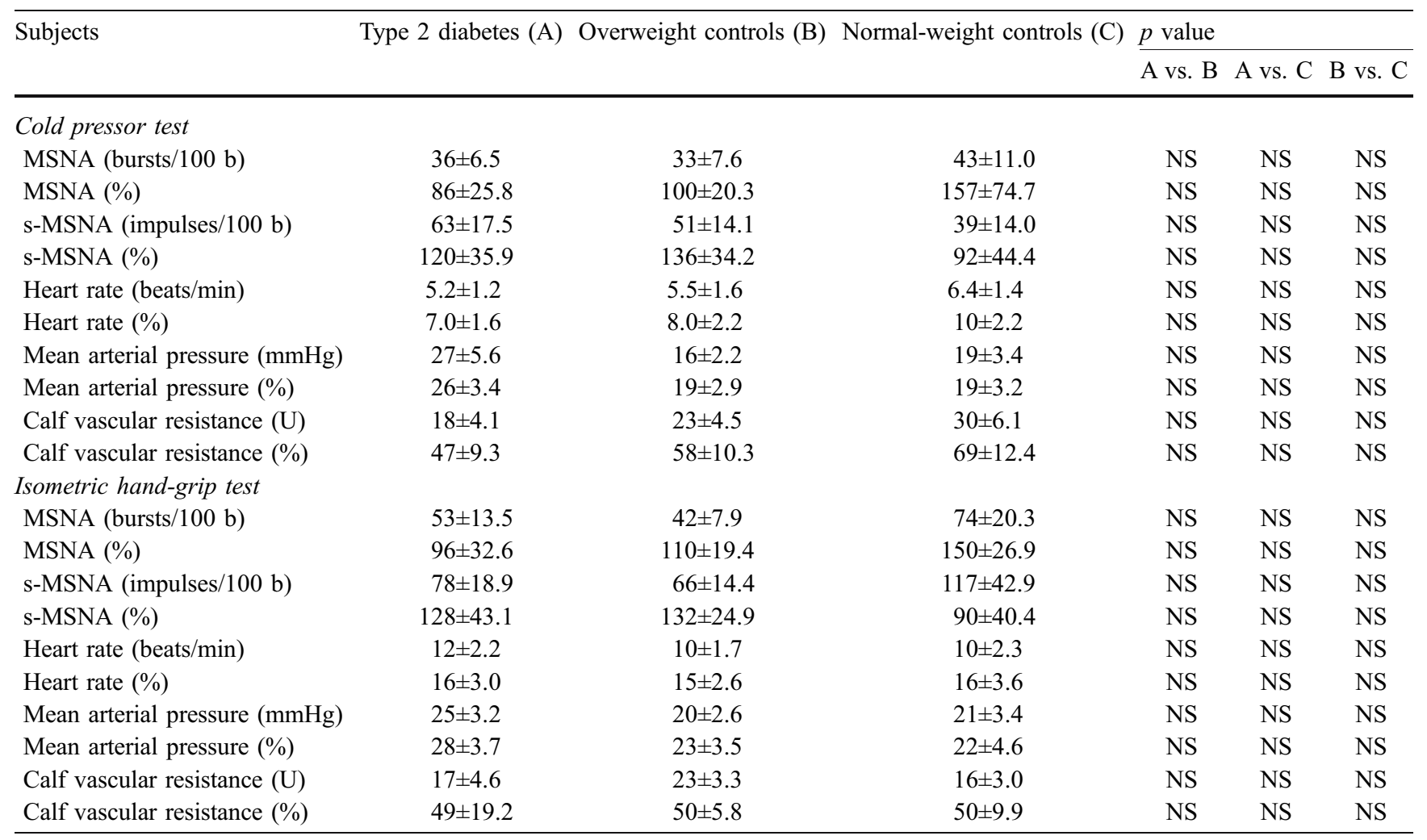

Response of variables to the two tests, presented as means \pm SEM. Analyses were performed using ANOVA post hoc tests. NS denotes $p>0.05$; $p$ values as shown. $100 \mathrm{~b}, 100$ cardia beats

neuropathy. Indeed, our findings that baroreceptor reflex vagal control or sympatho-vagal effects on the heart period were not impaired support our design. In addition, there was no impairment in the reflex responses of haemodynamic variables or sympathetic nerve activity to the isometric hand-grip exercise and cold pressor tests. In this, our findings differ from other investigations that found a decrease in vagal and sympathetic effects on the heart period $[14,17]$. Unlike our design, however, those reports either included patients with neuropathy [14] or did not explicitly exclude them [17]. We believe, therefore, that our findings were not confounded by any masking effect of neuropathy on possible changes in autonomic variables and their effect. Moreover, the results of our heart rate variability indices are comparable with previously defined data on normal ranges obtained in healthy humans using similar methods [37].

Our study design also avoided confounding effects when comparing patients with type 2 diabetes with control subjects. We avoided the potential effects of race, age, body weight, time of day, dietary sodium intake, arterial blood pressure level, visceral distension, alcohol, nicotine and exercise on the autonomic drive [36, 38-46]. These criteria were satisfied by closely matching the three groups and by using the same protocol for all subjects. Nevertheless, there were unavoidable differences, for example the group with type 2 diabetes was on antidiabetic therapy, the influence of which is unknown in our patients. However, it has previously been shown that metformin does not affect resting sympathetic nerve activity in insulin-resistant patients [9]. The effect of gliclazide on autonomic function is not known, though analysis of data in patients without this therapy did not affect our findings of greater sympathetic nerve activity in the group with type 2 diabetes. Therefore, it is unlikely that these agents caused the sympathetic nerve hyperactivity in the patients with type 2 diabetes.

The magnitude of sympathetic nerve hyperactivity in the diabetic group was about $60 \%$ relative to values found in the two control groups of the present study. In an attempt to achieve close matching between the normal groups and the diabetic group, we were not able to avoid including an overweight control group. The fact that excessive obesity [47] and increased visceral fat [48] have previously been associated with sympathetic nerve hyperactivity could indicate that the sympathetic hyperactivity in our diabetic group was even greater than that observed. However, there have been other reports showing that normal obese subjects without obstructive sleep apnoea have normal levels of sympathetic nerve activity [49] and that any increase in this activity over a wide range of body mass index can be attributed to a coexisting increase in age, hormonal levels and abdominal obesity [40, 50, 51]. Our findings are consistent with these reports, in that the normal-weight control group had a similar level of sympathetic nerve activity as the overweight group, at a time when both groups had no hormonal abnormality or obs- 
tructive sleep apnoea. Considering all these reports together with our findings, we suggest that sympathetic nerve hyperactivity in obese subjects could be explained by the presence of insulinaemia and insulin resistance.

Our new findings are consistent with those in a large number of reports in experimental animals and normal humans showing that an increase in plasma insulin levels causes a nonuniform activation of the sympathetic drive [1-12]. For instance, in experimental animals, administration of insulin into the cerebral ventricles or intravenously has been shown to increase sympathetic nerve activity in efferent lumbar nerves without affecting efferent renal or adrenal nerves $[6,7]$. Similarly in normal humans, acute hyperinsulinaemia with euglycaemic clamp increased the sympathetic drive to the forearm and not to the adrenomedullary region [8]. Even in insulin-resistant patients, acute insulinaemia was found to increase the central sympathetic drive to the periphery without affecting that supplying the renal region [9]. In patients with type 2 diabetes specifically it has been shown that the cardiac autonomic nervous system has a blunted response to insulin [11]. Also baseline measures of autonomic control of heart period variability in less insulin-sensitive and hyperinsulinaemic normal patients have been shown to be similar to insulin-sensitive normal subjects [12]. In the present report, a within-patient comparison has also shown a disparity of sympathetic activation in patients with type 2 diabetes and hyperinsulinaemia. Also, the sympathetic activation was correlated to insulin and HOMA-IR levels. We directly quantified sympathetic nerve activity, reflex responses and BRS, and used heart rate variability to examine relative sympathetic and vagal effects on the sinoatrial node. These considerations make it possible to argue that the cause of sympathetic nerve hyperactivity that occurred in the absence of changes in the other autonomic indicators in the group with type 2 diabetes was related to a central effect of the increased plasma insulin levels.

Although we did not examine the impact of sympathetic hyperactivity in our patients, the findings are consistent with the hypothesis that hyperinsulinaemia and insulin resistance are directly implicated in the pathogenesis of cardiovascular mortality that is associated with type 2 diabetes mellitus through sustained overactivation of the sympathetic nervous system. The higher risk of cardiovascular mortality in patients with type 2 diabetes has been attributed to numerous mechanisms including dyslipidaemia, coagulation abnormalities and endothelial dysfunction, as well as chronic sympathetic nerve activation induced by continuous chronic hyperinsulinaemia [52-54]. Our findings and those of others, regarding the involvement of sympathetic activation in the pathogenesis of hypertension [55] and the common association between type 2 diabetes and hypertension [53], indicate that the increased sympathetic drive to the periphery is one of the mechanisms leading to an increased risk of vascular complications in type 2 diabetes.

In summary, the present investigation has shown that patients with type 2 diabetes have disparate changes in autonomic control, which include activation of the sym- pathetic drive to the periphery whilst sparing cardiac autonomic control. Our findings, and those in experimental animals, suggest that the sympathetic activation is related to central effects of the hyperinsulinaemia found in these patients.

Acknowledgements The authors would like to thank The Hypertension Trust and St. James's Hospital Cardiology Research Fund for sponsoring this work, and Mrs. J.H. Corrigan for technical assistance.

\section{References}

1. Vollenweider P, Tappy L, Randin D et al (1993) Differential effects of hyperinsulinemia and carbohydrate metabolism on sympathetic nerve activity and muscle blood flow in humans. $\mathrm{J}$ Clin Invest 92:147-154

2. Rowe JW, Young JB, Minaker JJ, Stevens AL, Palotta JA, Landsberg L (1981) Effect of insulin and glucose infusions on sympathetic nervous system in normal man. Diabetes 30:219225

3. Lembo G, Napoli R, Capaldo B, Rendina V, Laccarino G, Volpe M (1992) Abnormal sympathetic overactivity evoked by insulin in the skeletal muscle of patients with essential hypertension. J Clin Invest 90:24-29

4. Berne C, Fagius J, Pollare T, Hjemdahl P (1992) The sympathetic response to euglycaemic hyperinsulinaemia. Evidence from microelectrode nerve recordings in healthy subjects. Diabetologia 35:873-879

5. Anderson EA, Hoffman RP, Balon TW, Sinkey CA, Mark AL (1991) Hyperinsulinemia produces both sympathetic neural activation and vasodilation in normal humans. J Clin Invest $87: 2246-2252$

6. Muntzel MS, Anderson EA, Johnson AK, Mark AL (1995) Mechanisms of insulin action on sympathetic nerve activity. Clin Exp Hypertens 17:39-50

7. Lu H, Duanmu Z, Scislo T, Dunbar JC (1998) The co-existence of insulin-mediated decreased mean arterial pressure and increased sympathetic nerve activity is not mediated by the baroreceptor reflex and differentially by hypoglycemia. Clin Exp Hypertens 20:165-183

8. Paramore DS, Fanelli CG, Shah SD, Cryer PE (1998) Forearm norepinephrine spillover during standing, hyperinsulinemia, and hypoglycemia. Am J Physiol 275:E872-E881

9. Gudbjornsdottir S, Friberg P, Elam M, Attvall S, Lonnroth P, Wallin BG (1994) The effect of metformin and insulin on sympathetic nerve activity, norepinephrine spillover and blood pressure in obese, insulin resistant, normoglycemic, hypertensive men. Blood Pressure 3:394-403

10. Bellavere F, Cacciatori V, Moghetti P et al (1996) Acute effect of insulin on autonomic regulation of the cardiovascular system: a study by heart rate spectral analysis. Diabet Med 13:709-714

11. Paolisso G, Manzella D, Rizzo MR et al (2000) Effects of insulin on the cardiac autonomic nervous system in insulinresistant states. Clin Sci 98:129-136

12. Bergholm R, Westerbacka J, Vehkavaara S, Seppala-Lindroos A, Goto T, Yki-Jarvinen H (2001) Insulin sensitivity regulates autonomic control of heart rate variation independent of body weight in normal subjects. J Clin Endocrinol Metab 86:14031409

13. Carstensen E, Sampson MJ, Savage MW, Ware M, Williams G, Yudkin JS (1998) Lack of relationship between sympathetic nervous system activity, measured by two circulating markers, and blood pressure in diabetic and nondiabetic subjects. J Diabetes Complicat 12:140-146 
14. Kondo K, Matsubara T, Nakamura J, Hotta N (2002) Characteristic patterns of circadian variation in plasma catecholamine levels, blood pressure and heart rate variability in type 2 diabetic patients. Diabet Med 19:359-365

15. Tack CJJ, Smits P, Willemsen JJ, Lenders JWM, Thien T, Lutterman JA (1196) Effects of insulin on vascular tone and sympathetic nervous system in NIDDM. Diabetes 45:15-22

16. Huggett RJ, Scott EM, Gilbey SG, Stoker JB, Mackintosh AF, Mary DA (2003) Impact of type 2 diabetes mellitus on sympathetic neural mechanisms in hypertension. Circulation 108:3097-3101

17. Toyry JP, Niskanen LK, Mantysaari MJ et al (1997) Do high proinsulin and C-peptide levels play a role in autonomic nervous dysfunction? Power spectral analysis in patients with non-insulin-dependent diabetes and nondiabetic subjects. Circulation 96:1185-1191

18. Liao D, Sloan RP, Cascio WE et al (1998) Multiple metabolic syndrome is associated with lower heart rate variability. The Atherosclerosis Risk in Communities Study. Diabetes Care 21:2116-2122

19. American Diabetes Association, American Academy of Neurology (1988) Consensus statement: report and recommendations of the San Antonio conference on diabetic neuropathy. Diabetes Care 11:592-597

20. Clinical Practice Recommendations American Diabetic Association (1995) Standardized measures in diabetic neuropathy. Diabetes Care 18:59-82

21. Report of the Expert Committee on the Diagnosis and Classification of Diabetes Mellitus (2003) Diabetes Care 26: S5-S20

22. Bonora E, Targher G, Alberiche $M$ et al (2000) Homeostasis model assessment closely mirrors the glucose clamp technique in the assessment of insulin sensitivity: studies in subjects with various degrees of glucose tolerance and insulin sensitivity. Diabetes Care 23:57-63

23. Mather KJ, Hunt AE, Steinberg HO et al (2001) Repeatability characteristics of simple indices of insulin resistance: implications for research applications. J Clin Endocrinol Metab 86: $5457-5464$

24. Greenwood JP, Stoker JB, Walker JJ, Mary DASG (1998) Sympathetic nerve discharge in normal pregnancy and pregnancy-induced hypertension. J Hypertens 16:617-624

25. Vallbo AB, Hagbarth KE, Torebjörk HE, Wallin BG (1979) Somatosensory, proprioceptive and sympathetic activity in human peripheral nerves. Physiol Rev 59:919-957

26. Macefield VG, Wallin BG, Vallbo AB (1994) The discharge behaviour of single vasoconstrictor motoneurones in human muscle nerves. J Physiol 481:799-809

27. Sundlöf G, Wallin BG (1977) The variability of muscle nerve sympathetic activity in resting recumbent man. J Physiol 272:383-397

28. Kautzner J, Hartikainen JE, Camm AJ, Malik M (1996) Arterial baroreflex sensitivity assessed from phase IV of the Valsalva maneuver. Am J Cardiol 78:575-579

29. Mark AL, Victor R, Nerhed C, Wallin BG (1985) Microneurographic studies of the mechanisms of sympathetic nerve responses to static exercise in humans. Circ Res 57:461-469

30. Kregel KC, Seals DR, Callister R (1992) Sympathetic nervous system activity during skin cooling in humans: relationship to stimulus intensity and pain sensation. J Physiol 454:359-371

31. Berger RD, Akselrod S, Gordon D, Cohen RJ (1986) An efficient algorithm for spectral analysis of heart rate variability. IEEE Trans Biomed Eng 33:900-904

32. Task force of the European Society of Cardiology and North American Society of Pacing and Electrophysiology (1996) Heart rate variability: standards of measurement, physiological interpretation, and clinical use. Circulation 93:1043-1065

33. Vinik AI, Maser RE, Mitchell BD, Freeman R (2003) Diabetic autonomic neuropathy. Diabetes Care 26:1553-1579
34. Aso Y, Fujiwara Y, Inukai T, Takemura Y (1998) Power spectral analysis of heart rate variation in diabetic patients with neuropathic foot ulceration. Diabetes Care 21:1173-1177

35. Caviezel F, Picotti GB, Margonato A et al (1982) Plasma adrenaline and noradrenaline concentrations in diabetic patients with and without autonomic neuropathy at rest and during sympathetic stimulation. Diabetologia 23:19-23

36. Masaoka S, Lev-Ran A, Hill LR, Vakil G, Hon EH (1985) Heart rate variability in diabetes: relationship to age and duration of the disease. Diabetes Care 8:64-68

37. Agelink MW, Malessa R, Baumann B et al (2001) Standardized tests of heart rate variability: normal ranges obtained from 309 healthy humans, and effects of age, gender, and heart rate. Clinic Auton Res 11:99-108

38. Calhoun DA, Mutinga ML, Collins AS, Wyss JM, Oparil S (1993) Normotensive blacks have heightened sympathetic response to cold pressor test. Hypertension 22:801-805

39. Ng AV, Callister R, Johnson DG, Seals DR (1993) Age and gender influence muscle sympathetic nerve activity at rest in healthy humans. Hypertension 21:498-503

40. Scherrer U, Randin D, Tappy L, Vollenweider P, Jequier E, Nicod P (1994) Body fat and sympathetic nerve activity in healthy subjects. Circulation 89:2634-2640

41. Hartikainen J, Tarkiainen I, Tahvanainen K, Mantysaari M, Lansimies E, Pyorala K (1993) Circadian variation of cardiac autonomic regulation during 24-h bed rest. Clin Physiol 13:185-196

42. Anderson EA, Sinkey CA, Lawton WJ, Mark AL (1989) Elevated sympathetic nerve activity in borderline hypertensive humans: evidence from direct intraneural recordings. Hypertension $14: 177-183$

43. Cox HS, Kaye DM, Thompson JM et al (1995) Regional sympathetic nervous activation after a large meal in humans. Clin Sci 89:145-154

44. Fagius H, Karhuvaara S (1989) Sympathetic activity and blood pressure increases with bladder distension in humans. Hypertension 14:511-551

45. Grassi GM, Somers VK, Renk WS, Abboud FM, Mark AL (1989) Effects of alcohol intake on blood pressure and sympathetic nerve activity in normotensive humans: a preliminary report. J Hypertens 7:S20-S21

46. Grassi G, Seravalle G, Calhoun DA et al (1994) Mechanisms responsible for sympathetic activation by cigarette smoking in humans. Circulation 90:248-253

47. Grassi G, Seravalle G, Cattaneo BM et al (1995) Sympathetic activation in obese normotensive subjects. Hypertension 25 : $560-563$

48. Alvarez GE, Beske SD, Ballard TP, Davy KP (2002) Sympathetic neural activation in visceral obesity. Circulation 106 2533-2536

49. Narkiewicz K, van de Borne PJ, Cooley RL, Dyken ME, Somers VK (1998) Sympathetic activity in obese subjects with and without obstructive sleep apnea. Circulation 98:772-776

50. Jones PP, Snitker S, Skinner JS, Ravussin E (1996) Gender differences in muscle sympathetic nerve activity: effect of body fat distribution. Am J Physiol 270:E363-E366

51. Sverrisdottir YB, Johannsson G, Jungersten L, Wallin BG, Elam M (2001) Is the somatotropic axis related to sympathetic nerve activity in healthy ageing men? J Hypertens 19:20192024

52. Kannel WB, McGee DL (1979) Diabetes and cardiovascular disease. The Framingham study. JAMA 241:2035-2038

53. Tack CJ, Smits P, Willemsen JJ, Lenders JW, Thien T, Lutterman JA (1996) Effects of insulin on vascular tone and sympathetic nervous system in NIDDM. Diabetes 45:15-22

54. Caprio S, Wong S, Alberti KGMM, King G (1997) Cardiovascular complications of diabetes. Diabetologia 40:B78-B82

55. Julius S, Nesbitt S (1996) Sympathetic overactivity in hypertension. A moving target. Am J Hypertens 9:113s-120s 